\title{
Polymorphic microsatellite loci in the rapid racerunner Eremias velox (Squamata: Lacertidae)
}

\author{
H. Li ${ }^{1}$, Z.-S. Zhou ${ }^{1}$, J. Guo ${ }^{1}$ and L.H. Lin ${ }^{2}$ \\ ${ }^{1}$ Jiangsu Key Laboratory for Biodiversity and Biotechnology, \\ College of Life Sciences, Nanjing Normal University, \\ Nanjing, Jiangsu, China \\ ${ }^{2}$ Hangzhou Key Lab for Animal Adaptation and Evolution, \\ School of Life Sciences, Hangzhou Normal University, \\ Hangzhou, Zhejiang, China \\ Corresponding author: L.H. Lin \\ E-mail: linlh@yahoo.cn
}

Genet. Mol. Res. 11 (4): 4707-4710 (2012)

Received March 2, 2012

Accepted June 8, 2012

Published October 9, 2012

DOI http://dx.doi.org/10.4238/2012.October.9.5

\begin{abstract}
We isolated and characterizated 12 polymorphic microsatellite loci in the rapid racerunner Eremias velox (Squamata: Lacertidae). The loci were screened in $37 \mathrm{E}$. velox individuals. The number of alleles ranged from 6 to 16. The observed heterozygosity ranged from 0.432 to 0.919 , and the expected heterozygosity ranged from 0.685 to 0.902 . These microsatellite markers should prove useful for population genetic studies of E. velox and other Eremias species.
\end{abstract}

Key words: Lacertidae; Lizard; Eremias velox; Microsatellite; Polymorphic microsatellite loci 


\section{INTRODUCTION}

The rapid racerunner Eremias velox is a small (up to $65 \mathrm{~mm}$ in length from snout to vent), oviparous lacertid lizard found in arid and semi-arid areas covered by sparse vegetation (Zhao, 1999). This lizard is widely distributed in Afghanistan, Azerbaijan, Georgia, Iran, Kazakhstan, Kyrgyzstan, Mongolia, Pakistan, Russia (lower Volga region, Kalmyk Steppe, and Daghestan), Tajikistan, Turkmenistan, Uzbekistan, and Northwest China (Eastern and Northern parts of the Tianshan Mountains in Xinjiang Uygur Autonomous Region and Eastwards to Gansu Corridor and Ejina in Inner Mongolia) (Zhao, 1999). Despite its wide geographical distribution, the ecology and biology of E. velox are poorly known. Incidental information on this species is obtained from studies addressing the phylogenetic relationship among Eremias lizards in China as well as intraspecific differentiation of E. velox in the Iranian Plateau and Central Asia based on 16S rRNA mitochondrial DNA sequences (Wan et al., 2007; Guo et al., 2011). Microsatellites are among the most efficient molecular markers for obtaining population genetic information. Here, we developed 10 highly polymorphic microsatellite markers that can be used to study the population genetics of E. velox, and then to determine identify effective conservation measures for this species.

\section{MATERIAL AND METHODS}

Microsatellites were obtained from an enriched library constructed using a modified protocol reported by Zane et al. (2002). Genomic DNA was extracted from the muscle tissue of an individual E. velox using the DNeasy Tissue Kit (Qiagen, Germany). Genomic DNA was digested using MseI restriction enzyme (New England Biolabs) and was ligated to a double-stranded MseI linker (MseI F: 5'-TACTCAGGACTCAT-3' and MseI R: 5'-GACGATGAGTCCTGAG-3') (Vos et al., 1995) for $3 \mathrm{~h}$ at $37^{\circ} \mathrm{C}$. The digested and ligated product was then amplified using an MseI-N primer (5'-GATGAGTCCTGAGTAAN-3') (Zane et al., 2002). After denaturation for $5 \mathrm{~min}$ at $95^{\circ} \mathrm{C}$, the amplified product was hybridized with a 5'-biotinylated $(\mathrm{CA})_{15}$ probe for $1 \mathrm{~h}$ at $65^{\circ} \mathrm{C}$. The hybridized probe DNA was captured using streptavidin-coated magnetic beads (Streptavidin Magnesphere Paramagnetic Particles, Promega). Unhybridized DNA was washed away, and the remaining DNA was eluted from the beads. The microsatellite-enriched DNA fragments were PCR-amplified again, and then ligated into pGEM-T Easy vectors (Promega), and transformed into competent DH5 $\alpha$ Escherichia coli cells (Takara). Recombinant clones were detected using blue/white screening. White clones were screened by PCR using 2 vector primers and the non-biotin-labeled $(\mathrm{CA})_{15}$ primer. Screening amplifications were performed as follows: $95^{\circ} \mathrm{C}$ for $5 \mathrm{~min}$, followed by 35 cycles of $95^{\circ} \mathrm{C}$ for $30 \mathrm{~s}, 57^{\circ} \mathrm{C}$ for $30 \mathrm{~s}$, and $72^{\circ} \mathrm{C}$ for $1 \mathrm{~min}$, and a final extension for $5 \mathrm{~min}$ at $72{ }^{\circ} \mathrm{C}$. PCR products were visualized on $2 \%$ agarose gels, and clones that generated 2 or more bands were selected and sequenced using an ABI PRISM 3730 automated sequencer (Applied Biosystems). Primers were designed for microsatellite inserts using the PRIMER 3 web-based program (http://frodo.wi.mit.edu; Rozen and Skaletsky, 2000).

\section{RESULTS AND DISCUSSION}

An enriched library of 265 white colonies was screened using the PCR-based technique, and 73 clones were identified by the presence of 2 or more bands on an agarose gel. A total of 
73 recombinant clones were sequenced. After discarding duplicates and those with short unique regions flanking the microsatellite array, 32 recombinant clones were suitable for primer design.

The levels of polymorphism at each loci were assessed in 37 individual $E$. velox that were sampled from 2 populations in Xinjiang Uygur Autonomous Region (Jinghe and Nileke) in the northwestern parts of China. PCR amplifications were conducted at the following temperatures: initial denaturation step at $95^{\circ} \mathrm{C}$ for $5 \mathrm{~min}$, followed by 30 cycles of $30 \mathrm{~s}$ at $95^{\circ} \mathrm{C}$, primer-specific annealing temperature for $30 \mathrm{~s}$ (Table 1), and $30 \mathrm{~s}$ at $72^{\circ} \mathrm{C}$, followed by a final extension for 10 $\min$ at $72^{\circ} \mathrm{C}$. Reactions were composed of $20 \mathrm{ng}$ template DNA, $7.5 \mu \mathrm{L}$ Ex Taq premix buffer (Takara), and $0.5 \mathrm{pM}$ of each of the forward and reverse primers in a total volume of $15 \mu \mathrm{L}$. Forward primers were labeled with FAM, HEX, or TAMRA. Labeled fragments were detected using capillary electrophoresis on an ABI PRISM 3730 xl DNA Analyzer (Applied Biosystems), and allelic sizes were determined using GENEMAPPER version 4.0 (Applied Biosystems).

\begin{tabular}{|c|c|c|c|c|c|c|c|c|}
\hline Locus & Primer sequence $\left(5^{\prime}-3^{\prime}\right)$ & Repeat motif & $\begin{array}{l}\text { Allele size } \\
\text { range (bp) }\end{array}$ & $\mathrm{Ta}\left({ }^{\circ} \mathrm{C}\right)$ & $N_{\mathrm{A}}$ & $H_{\mathrm{O}}$ & $\overline{H_{\mathrm{E}}}$ & Accession No. \\
\hline$\overline{\text { Ev-2 }}$ & $\begin{array}{l}\text { F: AGCGAGGCAGAGAAGTC (6FAM) } \\
\text { R: GAGTAATCCATCAAACCGT }\end{array}$ & $(\mathrm{CA})_{16}$ & $200-254$ & 52 & 13 & 0.750 & 0.813 & JN592483 \\
\hline Ev-9 & $\begin{array}{l}\text { F: AACCTTTCAAAAACTGC(TAMRA) } \\
\text { R: ACTGTGAGGACACTGGAC }\end{array}$ & $\begin{array}{l}(\mathrm{CT})_{6} \mathrm{GT}(\mathrm{CT})_{3} \\
\mathrm{GT}(\mathrm{CT})_{6}(\mathrm{CA})_{7}\end{array}$ & 174-196 & 55 & 9 & 0.622 & 0.685 & JQ671014 \\
\hline Ev-13 & $\begin{array}{l}\text { F: GCTTGTTGGGGATTTGA(TAMRA) } \\
\text { R: CTTAGCCACTCTGTCTGTTG }\end{array}$ & $(\mathrm{CA})_{21}$ & $241-275$ & 52 & 15 & 0.919 & 0.902 & JQ671015 \\
\hline Ev-54 & $\begin{array}{l}\text { F: ACATACCATTTGACTTCC(HEX) } \\
\text { R: GTTTAGAGGCACATTCC }\end{array}$ & $(\mathrm{CA})_{20}$ & $184-236$ & 55 & 15 & 0.865 & 0.886 & JQ671016 \\
\hline Ev-64 & $\begin{array}{l}\text { F: GAAAAGACCCAAATCCACC(TAMRA) } \\
\text { R: TGAAGGCAAAAGGCAGG }\end{array}$ & $(\mathrm{CA})_{20}$ & $238-272$ & 60 & 6 & 0.784 & 0.771 & JQ671017 \\
\hline Ev-70 & $\begin{array}{l}\text { F: TGGCTGCCCTTACTCGT (HEX) } \\
\text { R: TCCAGGAACTGAAAGAACAC }\end{array}$ & $(\mathrm{CAC})_{7} \mathrm{TA}(\mathrm{CA})_{15}$ & $124-212$ & 55 & 16 & 0.432 & $0.795^{*}$ & JN592485 \\
\hline Ev-94 & $\begin{array}{l}\text { F: GCAAGAAAGATAACCCCT (6FAM) } \\
\text { R: TCTGCTGAAGTCAATGGA }\end{array}$ & $(\mathrm{CT})_{17}(\mathrm{CA})_{14}$ & $225-251$ & 52 & 12 & 0.838 & 0.886 & JN592487 \\
\hline Ev-95 & $\begin{array}{l}\text { F: TATGCTTGGTTAGGGGTAG (HEX) } \\
\text { R: GGGACTTTTGTAAATCTTGC }\end{array}$ & $(\mathrm{CA})_{21}$ & $135-169$ & 52 & 13 & 0.784 & 0.882 & JN592488 \\
\hline Ev-96 & $\begin{array}{l}\text { F: TTTAGCAGAGCAGGGAGG(HEX) } \\
\text { R: GCTGAAAGGGCTGGAGG }\end{array}$ & $(\mathrm{CA})_{21}$ & $100-118$ & 60 & 9 & 0.919 & 0.820 & JQ671018 \\
\hline Ev-103 & $\begin{array}{l}\text { F: GAGCATGGGAGAGCAGT (HEX) } \\
\text { R: CACAATGGAAGTGAGAATC }\end{array}$ & $(\mathrm{CA})_{18}$ & $256-274$ & 62 & 9 & 0.784 & 0.814 & JN592490 \\
\hline Ev-106 & $\begin{array}{l}\text { F: AAAGGGAAATCCTATGC (TAMRA) } \\
\text { R: GCTGCTCACTGCTCTAAG }\end{array}$ & $(\mathrm{CA})_{20}$ & $219-259$ & 55 & 14 & 0.784 & 0.793 & JN592491 \\
\hline Ev-111 & $\begin{array}{l}\text { F: CGGAACGGATTGTGGTC(6FAM) } \\
\text { R: AGCAGAACGGCTGAAGA }\end{array}$ & $(\mathrm{CA})_{20}$ & $185-211$ & 60 & 10 & 0.487 & $0.800^{*}$ & JQ671019 \\
\hline
\end{tabular}

*Indicates significant deviations from Hardy-Weinberg equilibrium after sequential Bonferroni's correction. $\mathrm{Ta}=$ annealing temperature; $N_{\mathrm{A}}=$ number of alleles; $H_{\mathrm{O}}=$ observed heterozygosity; $H_{\mathrm{E}}=$ expected heterozygosity.

The expected and observed heterozygosities were calculated using the CERVUS 3.0 software (Marshall et al., 1998). Deviation from Hardy-Weinberg equilibrium (HWE) and linkage disequilibrium at each locus were measured using GENEPOP version 4.0 (Rousset, 2008). Results of these tests were corrected for multiple comparisons by applying sequential Bonferroni's corrections (Rice, 1989). The Micro-Checker (Van Oosterhout et al., 2004) analysis was used to estimate the most probable cause of deviation from HWE.

Among the 24 successfully amplified primer pairs, 12 loci were polymorphic in the 37 individuals. The number of alleles per locus ranged from 6 to 16, whereas the observed and expected heterozygosities ranged from 0.432 to 0.919 and 0.685 to 0.902 , respectively (Table 1 ). 
After Bonferroni's correction (Rice, 1989), 2 loci (EV-70 and EV-111) significantly deviated from HWE. The deficiency in heterozygotes could be due to the presence of null alleles, as suggested by Micro-Checker (Van Oosterhout et al., 2004). Ev-13 and Ev-103 exhibited significant linkage disequilibrium following sequential Bonferroni's correction. The major goals for conservation of this species are to sustain genetic diversity and to prevent genetic erosion. To date, no microsatellite loci have been reported for E. velox. Therefore, the primers described here will be valuable tools for examining the genetic diversity, gene flow, and population structure of $E$. velox.

\section{ACKNOWLEDGMENTS}

Research supported by grants from the Chinese Ministry of Education (\#20103207120009), the Natural Science Foundation of China (\#31070339, \#31101635), the Zhejiang Department of Science and Technology for Innovation Teams (\#2010R50039), and the Natural Science Foundation of Jiangsu Province (\#BK2012849). The authors would like to thank Ce Chen and Lu-Xi Mao for their help during the research.

\section{REFERENCES}

Guo X, Dai X, Chen D, Papenfuss TJ, et al. (2011). Phylogeny and divergence times of some racerunner lizards (Lacertidae: Eremias) inferred from mitochondrial 16S rRNA gene segments. Mol. Phylogenet. Evol. 61: 400-412.

Marshall TC, Slate J, Kruuk LE and Pemberton JM (1998). Statistical confidence for likelihood - based paternity inference in natural populations. Mol. Ecol. 7: 639-655.

Rice WR (1989). Analyzing tables of statistical tests. Evolution 43: 223-225.

Rousset F (2008). Genepop'007: a complete re-implementation of the genepop software for Windows and Linux. Mol. Ecol. Resour. 8: 103-106.

Rozen S and Skaletsky HJ (2000). PRIMER 3 on the WWW for General Users and for Biologist Programmers. In: Bioinformatics Methods and Protocols Methods in Molecular Biology (Krawetz S and Misener S, eds.). Humana Press, Totowa, 365-386.

Van Oosterhout C, Hutchinson WF, Wills DPM and Shipley P (2004). MICRO-CHECKER: software for identifying and correcting genotyping errors in microsatellite data. Mol. Ecol. Notes 4: 535-538.

Vos P, Hogers R and Bleeker M (1995). AFLP: a new technique for DNA fingerprinting. Nucleic Acids Res. 23: 44074414.

Wan LX, Sun SH, Jin YT, Yan YF, et al. (2007). Molecular phylogeography of the Chinese lacertids of the genus Eremias (Lacertidae) based on 16S rRNA mitochondrial DNA sequences. Amphibia-Reptilia 28: 33-41.

Zane L, Bargelloni L and Patarnello T (2002). Strategies for microsatellite isolation: a review. Mol. Ecol. 11: 1-16.

Zhao KT (1999). Lacertidae. In: Fauna Sinica, Reptilia (Zhao EM, Zhao KT and Zhou KY, eds.). Vol. 2. Science Press, Beijing, 219-242. 